\title{
Treatment with p33 Curtails Morbidity and Mortality in a Histone-Induced Murine Shock Model
}

\author{
Johannes Westman $^{\mathrm{a}}$ Emanuel Smeds $^{\mathrm{a}}$ Linda Johansson $^{\mathrm{b}}$ Matthias Mörgelin ${ }^{\mathrm{a}}$ \\ Anders I. Olin ${ }^{a}$ Erik Malmström ${ }^{a} \quad$ Adam Linder $^{a}$ Heiko Herwald ${ }^{a}$ \\ ${ }^{a}$ Division of Infection Medicine, Department of Clinical Sciences, Biomedical Center, Lund, Lund, and ${ }^{\mathrm{b}}$ Center \\ for Infectious Medicine, Department of Medicine, Karolinska Institutet, Karolinska University Hospital Huddinge, \\ Stockholm, Sweden
}

\section{Key Words}

Extracellular histones · Antimicrobial peptides .

Host defense $\cdot$ Immune response $\cdot$ Septic shock

\begin{abstract}
Collateral damage caused by extracellular histones has an immediate impact on morbidity and mortality in many disease models. A significant increase in the levels of extracellular histones is seen in critically ill patients with trauma and sepsis. We showed that histones are released from necrotic cells in patients with invasive skin infections. Under in vitro conditions, endogenous $\mathrm{p} 33$, an endothelial surface protein also known as the $\mathrm{gClq}$ receptor, interacts with histones released from damaged endothelial cells. Functional analyses have revealed that recombinantly expressed p33 completely neutralizes the harmful features of histones, i.e. hemolysis of erythrocytes, lysis of endothelial cells and platelet aggregation. We also noted that mice treated with a sublethal dose of histones developed severe signs of hemolysis, thrombocytopenia and lung tissue damage already $10 \mathrm{~min}$ after inoculation. These complications were fully counteracted when p33 was administered together with the histones. Moreover, application of p33 significantly improved survival in mice receiving an otherwise lethal
\end{abstract}

dose of histones. Together, our data suggest that treatment with p33 is a promising therapeutic approach in severe infectious diseases.

(c) 2014 S. Karger AG, Basel

\section{Introduction}

In recent years, the role of extracellular histones in systemic inflammatory diseases has attracted a great deal of attention. Histones are normally found in the nucleus where they have an important function in the structural organization of DNA fibers and their packing in the chromosome. Mobilization of histones into the extracellular space is mainly a consequence of cell necrosis, but can also occur during neutrophil extracellular trap (NET) formation and upon apoptosis $[1,2]$. When released from dying or NETotic cells, histones can evoke a number of systemic reactions seen, for instance, in patients with benign and malignant tumors, trauma-associated lung injury, systemic lupus erythematosus or malaria [3-6]. Notably, amongst the highest concentrations of histones are measured in samples of plasma from patients with traumatic injury or who are suffering from severe infectious diseases $[3,7,8]$. Evidence is accumulating that the re- 
lease of histones can contribute to considerable complications including the induction of massive inflammatory reactions (cytokine storm), thrombocytopenia, thrombin generation and host-cell necrosis [9-12]. Indeed, there are many reports showing that the levels of histones in patients correlate well with disease severity $[3,4,6,13]$.

Under pathological conditions, histones are known to evoke severe endothelial damage and, when injected intravenously (i.v.) at high doses, they can cause death in mice within minutes. In 2009, Xu et al. [8] established a lethal LPS murine sepsis model to show that endotoxinchallenged mice are rescued when treated with an antibody against the histone $\mathrm{H} 4$. Moreover, it was found that exogenously applied activated protein $\mathrm{C}$ can cleave histones into nontoxic fragments. Application of heparin has also been described to protect mice by neutralizing extracellular histones $[8,9]$ and similar results have been reported when C-reactive protein and thrombomodulin are used $[14,15]$. Together, these findings suggest that histones are an interesting target for drug development.

We undertook this study to identify novel proteins that can counteract the toxic effect of extracellular histones. We report that $\mathrm{p} 33$ (also referred to as globular C1q receptor) binds to and neutralizes all subclasses of histones. In addition, we show that $\mathrm{p} 33$ dramatically improves survival in mice challenged with an otherwise lethal injection of histones. The implication of these data is that p33 can be used as treatment in severe infectious diseases.

\section{Materials and Methods}

Peptides and Antibodies

Recombinant histones H1, H2A, H2B, H3.1 and H4 were purchased from Bionordika (Stockholm, Sweden) and bovine calf thymus histones (CTH) from Roche (Basel, Switzerland). Histoneand p33-derived peptides (Biopeptide Co., San Diego, Calif., USA) were synthesized. Polyclonal antisera to $\mathrm{p} 33$ were raised in rabbits (Innovagen AB, Lund, Sweden). Peroxidase-conjugated goat antirabbit immunoglobulin $\mathrm{G}$ was purchased from Bio-Rad Laboratories (Berkeley, Calif., USA). Antibodies against histone H4 (polyclonal chip-grade anti-histone H4) and p33 (mouse monoclonal anti-gC1qr, clone 60.11) were from Abcam (Cambridge, UK).

\section{Bacterial Strains}

The Escherichia coli strain ATCC 25922 was from the Department of Bacteriology, Lund University Hospital, Sweden.

\section{Ethics Statement}

The institutional review board at the Lund University Hospital approved the study (Protocol \#790/2005). Plasma samples and tissue biopsies (Lund University Hospital, Sweden and University of Toronto, Canada) were taken with a written informed consent and the study included patients $>18$ years of age. The animal use pro- tocols (\#M108-10 and \#M327-12) were approved by the local Institutional Animal Care and Use Committee (IACUC) of Malmö/ Lund, Sweden. All animals were handled according to the Swedish Animal Welfare Act (SFS 1988:534).

\section{Animals}

Female Balb/c mice were from Charles River (Sulzfeld, Germany) and were at least 8 weeks old at the initiation of the experiments.

\section{Blood Collection}

Peripheral venous blood was collected from healthy human individuals into 2.7- $\mathrm{ml}$ 0.109-M buffered sodium citrate tubes (Becton Dickinson). Citrated blood was centrifuged (at 2,000 $\mathrm{g}$ and $4^{\circ} \mathrm{C}$ for $10 \mathrm{~min}$ ). The plasma supernatant was then aliquoted and stored at $-80^{\circ} \mathrm{C}$.

\section{Purification of Recombinant Maltose-Binding Protein-p33}

(MBP-p33)

The pMAL-c2 expression vector (New England Biolabs, Ipswich, Mass., USA) and E. coli XL1-Blue strain (Stratagene, Heidelberg, Germany) were used to express recombinant MBP-p33. Purification and removal of the MBP-tag was performed as previously described [16].

\section{LPS Removal from $M B P-p 33$}

Concentrated MBP-p33 was diluted 1:10 in cold 10\% (v/v) Triton X-114 (Sigma Aldrich). The protein-detergent mixture was incubated for $30 \mathrm{~min}$ at $4^{\circ} \mathrm{C}$ for Triton X-114 to allow the detergent to bind up free LPS. Samples were then incubated for $15 \mathrm{~min}$ at $37^{\circ} \mathrm{C}$ before centrifuging them at $15,000 \mathrm{~g}$ for $15 \mathrm{~min}$. The top aqueous phase containing MBP-p33 was carefully removed and placed in a new tube, and the detergent phase containing LPS was discarded. This procedure was repeated twice. To measure LPS, the ToxinSensor Gel Clot Endotoxin Assay kit (Genscript, Piscataway, N.J., USA) was used according to the manufacturer's instruction. The LPS-free MBP-p33 was run through PD-10 columns (GE Healthcare, Uppsala, Sweden) at least 3 times to remove residual detergent and concentrated using an Amicon Ultra Centrifugal Filter device with a 50,000-unit nominal molecular weight limit (Millipore, Billerica, Mass., USA).

\section{Immunostaining of Tissue Sections}

Snap-frozen tissue collected from the center of infection from a patient with severe cellulitis caused by Streptococcus pyogenes of M1 serotype was stained. The biopsy was cryostat-sectioned to $8 \mu \mathrm{m}$ and fixed in ice-cold acetone. Immunofluorescence staining was performed with anti-histone $\mathrm{H} 4$ (Abcam, Cambridge, UK) as previously described [17] and visualized using a Nikon A1R confocalmicroscope(NikonInstruments, Amstelveen, TheNetherlands). It should be noted that the antibody did not penetrate intact cells and thus no intracellular staining was seen.

\section{Depletion Column and In-Solution Digestion for Mass} Spectrometry

High abundant plasma proteins were removed with a Human 14 Multiple Affinity Removal spin cartridge as described by the manufacturer (Agilent Technologies, Santa Clara, Calif., USA). Depleted plasma was concentrated using a spin concentrator for proteins ( $5 \mathrm{kDa}$ cut-off) according to the specific manufacturer's 
protocols (Agilent Technologies, Santa Clara, Calif., USA). Plasma protein mixtures in solution were digested and prepared for mass spectrometry (MS) analysis as previously described [18].

\section{MS Data Acquisition and Processing}

Biognosys HRM kit (Biognosys AG, Schlieren, Switzerland) was spiked to each sample according to the manufacturer's instructions. Each sample was analyzed on a ThermoScientific EASY-nLC II coupled to a QExactive mass spectrometer, using the LC-method as previously described, except for a longer gradient of $120 \mathrm{~min}$. The mass spectrometer was operated using the 'Full MS/ AIF' method template. The full precursor mass range of 400-1,220 $\mathrm{m} / \mathrm{z}$ was split into 20 overlapping segments with sizes between 26 and $77 \mathrm{~m} / \mathrm{z}$. Each segment used the following instrument parameter. A precursor scan of the mass range of the segments was acquired with a resolution of 17,500 and a maximum ion-trapping time of $1 \mathrm{~ms}$ only. Precursor ions within this mass range were isolated and fragmented all together by HCD with an AGC target value of 5E5 and an NCE of 25.0 (stepped by 10\%). The mass spectra of the fragment ions were acquired with a resolution of 35,000 for a mass range of $200-1,800 \mathrm{~m} / \mathrm{z}$. Raw files were processed together with the generated assay library using Biognosys Spectronaut software [19]. Briefly, Spectronaut applies a decoy scoring approach to calculate a false discovery rate for each identification [20].

\section{Immunoelectron Microscopy}

Epon sections of human umbilical vein endothelial cells (HUVEC) and lung biopsies infected with the S. pyogenes AP1 strain were labeled with gold-conjugated antibodies against histone $\mathrm{H} 4(10 \mathrm{~nm})$ and p33 $(5 \mathrm{~nm})$. Molecular complexes between p33 and histone/gold conjugates $(5 \mathrm{~nm})$ were negatively stained with $0.75 \%$ uranyl formate. Specimens were subjected to transmission electron microscopy as previously described [21] and examined in a Philips/FEI CM 100 transmission electron microscope at the Core Facility for Integrated Microscopy, Panum Institute, University of Copenhagen.

\section{ELISA}

Microtiter plates were coated overnight with histones (250 nM) or histone-derived peptides $(1 \mu \mathrm{M})$ in coating buffer $(15.9 \mathrm{mM}$ $\mathrm{Na}_{2} \mathrm{CO}_{3}, 30 \mathrm{mM} \mathrm{NaHCO} 3, \mathrm{pH} 9.6$ ) and stored overnight at $4{ }^{\circ} \mathrm{C}$. Plates were then washed 3 times in deionized water, blocked in phosphate-buffered saline containing $0.05 \%$ Tween-20 (PBST) and $0.5 \%$ bovine serum albumin for $30 \mathrm{~min}$ at $37^{\circ} \mathrm{C}$. After a washing step, plates were probed with MBP-p33 (33 nM) for $1 \mathrm{~h}$ at $37^{\circ} \mathrm{C}$ and binding was detected with a polyclonal antisera against $\mathrm{MBP}$ p33 $(1: 5,000)$ and a peroxidase-conjugated antibody against rabbit $\operatorname{IgG}\left(1: 2,500\right.$ for $1 \mathrm{~h}$ at $37^{\circ} \mathrm{C}$, Bio-Rad Laboratories). All incubations were followed by a washing step in PBST. When performing a competitive ELISA, microtiter plates were coated overnight with histones $(100 \mathrm{nM})$ and probed with $13 \mathrm{nM} \mathrm{MBP}-\mathrm{p} 33$ in the presence of different p33-derived peptides $(50 \mu \mathrm{M})$ for $1 \mathrm{~h}$ at $37^{\circ} \mathrm{C}$. Binding was detected as described above.

\section{Surface Plasmon Resonance}

Analyses were performed with a BIAcore 2000 instrument (GE Healthcare) using the Sensor Chip CM3 technology at $25^{\circ} \mathrm{C}$ in a running buffer consisting of PBS without additives. MBP-p33 was diluted in sodium acetate $(10 \mathrm{mM}, \mathrm{pH} 4.0)$ and 1,338 response units were immobilized via amine coupling to each flow cell. One flow cell on each sensor chip was subjected to the coupling reaction but without protein, and was used as a control in each experiment for bulk resonance changes. Histones were injected in diluted concentrations $(31.25,62.5,125,250$ and $500 \mathrm{nM})$ over the coated surfaces (at $45 \mu \mathrm{l} / \mathrm{min}$ in running buffer). Regeneration of MBP-p33 surfaces was obtained by injection of $200 \mu \mathrm{l}$ of $2 \mathrm{M} \mathrm{NaCl}$ and $10 \mathrm{mM}$ glycine ( $\mathrm{pH}$ 2), and followed by an extensive wash procedure.

Sensorgrams were displayed using the BIA Evaluation 4.1 software (GE Healthcare). After X and Y normalization of data, the blank curves from the control flow cell of each concentration were subtracted, and the association $\left(\mathrm{k}_{\mathrm{a}}\right)$ and dissociation $\left(\mathrm{k}_{\mathrm{d}}\right)$ rate constants were determined using a Langmuir model for fitting in the evaluation program. The equilibrium dissociation constants $\left(K_{D}\right)$ were calculated from these values.

\section{Viable Count Assay}

An overnight culture of E. coli strain ATCC 25922 was grown to mid-log phase in $3 \%(\mathrm{w} / \mathrm{v})$ tryptic soy broth medium at $37^{\circ} \mathrm{C}$ on rotation. Bacteria were washed in $10 \mathrm{ml}$ of cold $10-\mathrm{mM}$ Tris containing $5 \mathrm{mM}$ glucose, $\mathrm{pH} 7.5$ and diluted $\left[2 \times 10^{6}\right.$ colony-forming units $(\mathrm{CFU}) / \mathrm{ml}]$ and kept on ice. One volume of bacteria was incubated (for $1 \mathrm{~h}$ at $37^{\circ} \mathrm{C}$ on rotation) with one volume of histones $(500 \mathrm{nM})$, in the presence or absence of $2.5 \mu \mathrm{M}$ MBP-p33. All samples were diluted and plated on Todd-Hewitt agar plates. The following day, antibacterial activity was determined by counting the number of CFU on the plates.

\section{in vitro Hemolysis Assay}

Citrated blood $\left(1 \mathrm{ml}\right.$ ) was centrifuged (at $2,000 \mathrm{~g}$ and $4{ }^{\circ} \mathrm{C}$ for $10 \mathrm{~min}$ ), and plasma was removed and replaced by $1 \mathrm{ml}$ PBS. The washing step was repeated twice. Histones were diluted in PBS to $10 \mu \mathrm{M}$ in the presence or absence of $10 \mu \mathrm{M}$ of MBP-p33 to a final volume of $60 \mu \mathrm{l}$. Tox-7 lysis buffer and PBS served as a positive and negative control, respectively. Three microliters of washed blood cells $(5 \% \mathrm{v} / \mathrm{v})$ were added to each sample and the samples were incubated (for $60 \mathrm{~min}$ at $37^{\circ} \mathrm{C}$ on rotation) in a heat block. All samples were centrifuged (at 2,000 $\mathrm{g}$ and room temperature for $10 \mathrm{~min}$ ) and the supernatants were transferred to microtiter plates. Absorbance of hemoglobin was measured at $540 \mathrm{~nm}$ and histone-induced hemolysis was expressed as a percentage of Tox-7 lysis-induced hemolysis.

\section{Histone-Induced Cytotoxicity}

The assay was performed with EA.hy926 cells (a permanent human hybrid endothelial cell line) [22] cultured in DMEM containing $10 \%$ fetal bovine serum, $100 \mathrm{mM}$ hypoxanthine, $0.4 \mathrm{mM}$ aminopterin, $16 \mathrm{mM}$ thymidine, $100 \mathrm{mg} / \mathrm{ml}$ streptomycin and 100 $\mathrm{U} / \mathrm{ml}$ penicillin. The adherent cells were grown confluent in microtiter plates and washed in $200 \mu \mathrm{l}$ of phenol-free DMEM prior to the experiment. Histones $(2-4 \mu \mathrm{M})$ were diluted in phenol-free DMEM and preincubated with MBP-p33 $(10 \mu \mathrm{M})$ for $1 \mathrm{~h}$ at $37^{\circ} \mathrm{C}$. Samples were transferred to the endothelial cells and incubated overnight (for $16 \mathrm{~h}$ at $37^{\circ} \mathrm{C}$ and $5 \% \mathrm{CO}_{2}$ ). Supernatants were then transferred onto new microtiter plates and one volume of lactate dehydrogenase $(\mathrm{LDH})$-substrate mix was added. $\mathrm{LDH}$ release was measured at $490 \mathrm{~nm}$ using the Tox-7 kit (Sigma Aldrich) according to the manufacturer's instructions. Histone-induced LDH release was calculated as a percentage of Tox-7 lysis-induced LDH release. 
Platelet Aggregometry

Platelet aggregation was determined by measuring the optical density of stirred platelet-rich plasma over time using an aggregometer (Chrono-Log Corp., Havertown, Pa., USA). Citrated blood from healthy donors was centrifuged at $180 \mathrm{~g}$ for $10 \mathrm{~min}$ to obtain platelet-rich plasma. The aggregometer was standardized by placing platelet-poor plasma in one channel to represent $100 \%$ light transmittance. Platelet aggregation was measured in another channel when CTH $(300 \mu \mathrm{g} / \mathrm{ml})$ were added to platelet-rich plasma in the presence or absence of MBP-p33 (0.65-6.2 $\mu \mathrm{M})$. Chart recordings were monitored for up to $12 \mathrm{~min}$.

\section{Determination of the MBP-p33 Concentration in Murine}

Plasma Samples

Eight mice were injected with MBP-p33 (1.5 mg/animal). Two mice were euthanized after 3 and $30 \mathrm{~min}$ and 2 and $6 \mathrm{~h}$. Blood was drawn through cardiac puncture and immediately transferred into tubes with $70 \mu \mathrm{l}$ buffered sodium citrate. Plasma was separated from cells by a centrifugation step ( $180 \mathrm{~g}$ for $10 \mathrm{~min}$ ) and stored at $-80^{\circ} \mathrm{C}$ until use. Microtiter plates were coated overnight with a monoclonal antibody against anti-p33 (1:1,000, clone 74.5.2, Covance). Plates were then washed in PBST, blocked in blocking buffer (i.e. containing $0.5 \%$ bovine serum albumin), and the murine plasma samples were probed with $100 \mu \mathrm{l}$. Binding was detected with polyclonal sera against p33 (1:5,000) and a peroxidase-conjugated antibody against rabbit IgG.

\section{in vivo Imaging of $M B P-p 33$ in Mice}

A fluorophore (VivoTag 680XL) was used to label MBP-p33 using a protein labeling kit (PerkinElmer) according to the manufacturer's instructions. Mice were anesthetized with isofluorane and then injected with fluorescent MBP-p33. The distribution was visualized at 3 and $30 \mathrm{~min}$, at 2 and $6 \mathrm{~h}$ and once a day for 7 days using the In vivo Imaging System from PerkinElmer (IVIS Spectrum). PBS-injected mice served as a control. Images were generated using the Living Image v 4.3.1 software (Caliper LifeSciences, Hopkinton, Mass., USA).

\section{Histone-Induced Thrombocytopenia and Hemolysis}

Mice received an i.v. tail-vein injection $(200 \mu \mathrm{l})$ of $0.75 \mathrm{mg}$ CTH (nonlethal dose) in the absence or presence of $1.5 \mathrm{mg} \mathrm{MBP}-\mathrm{p} 33$. Sterile PBS was used as a control. Mice were euthanized with $\mathrm{CO}_{2}$ inhalation followed by cervical dislocation. Blood was drawn by cardiac puncture using a syringe filled with $70 \mu$ of buffered sodium citrate and then transferred into K2 Microtainer MAP tubes precoated with $1 \mathrm{mg}$ EDTA (Becton Dickinson). For platelet analysis, blood cells and platelet counts were determined by a Vetscan HM5 (Abaxis, Union City, Calif., USA) according to the manufacturer's instructions. For hemolysis assay, blood was centrifuged (at $180 \mathrm{~g}$ for $10 \mathrm{~min}$ ), and hemolysis in these plasma samples was measured at $540 \mathrm{~nm}$.

\section{Survival Study}

Mice received an i.v. tail-vein injection $(200 \mu \mathrm{l})$ of $1.5 \mathrm{mg} \mathrm{CTH}$ (lethal dose) in the absence or presence of $1.5 \mathrm{mg}$ MBP-p33. Moribund animals were euthanized and counted as dead at the time point of euthanasia.

\section{Statistical Analysis}

Statistical analysis was performed using GraphPad Prism, $\mathrm{v}$ 6.00. The $\mathrm{p}$ value was determined by using the unpaired $t$ test (comparison of 2 groups) or the log-rank test (comparison of sur- vival). If not otherwise mentioned, all experiments were performed at least 3 times. The bars in the figures indicate the standard error of the mean.

\section{Results}

\section{Extracellular Histones Are Found in Patients with}

Invasive Skin Infections and Septic Shock

Elevated levels of circulating nucleosomes have been reported in patients with severe infectious diseases $[1,4$, 6]. However, little is known about whether skin infections and subsequent necrosis serve as a source of extracellular histones. To address this question, we employed immunofluorescence microscopy and studied biopsies from a patient with deep tissue destruction (cellulitis) caused by $S$. pyogenes. Immunostaining with an antibody against extracellular histone $\mathrm{H} 4$ revealed large areas without any cell integrity where the dissemination of extracellular histone H4 and extracellular DNA was recorded (fig. 1a). When biopsies from a healthy donor were analyzed under the same experimental conditions, we found mainly intact intracellular DNA and only minor extracellular levels of the histone (fig. 1b). Under severe conditions, skin infections can cause systemic reactions and evoke lifethreatening complications including sepsis, severe sepsis and septic shock $[23,24]$. In order to determine the upregulation of circulating histone $\mathrm{H} 4$ in these patients, we used MS analysis. To this end, levels of histone $\mathrm{H} 4$ in plasma were analyzed in septic-shock patients and in healthy donors. Histone $\mathrm{H} 4$ was detectable in all 5 patients, but the protein was not found in any of the control samples (fig. 1c). Taken together, the analyses of patient samples revealed that histone $\mathrm{H} 4$ is found in tissue biopsies and plasma samples from patients with severe infectious diseases.

\section{Necrosis of Endothelial Cells Leads to Complex Formation of Histones and Endogenous p33}

In the next series of experiments, we wished to study the fate of histones released from necrotic cells under in vitro conditions. We decided to use HUVEC and induced necrosis by adding $S$. pyogenes bacteria. Cell necrosis and histone release were then followed by immunodetection with a gold-labeled antibody against histone $\mathrm{H} 4$ and subsequent transmission electron microscopy. Figure 1d illustrates that the histone was not released from intact cells, while streptococcal-induced cell damage led to a loss of endothelial cell membrane integrity and the mobilization of histone $\mathrm{H} 4$ into the extracellular surrounding 

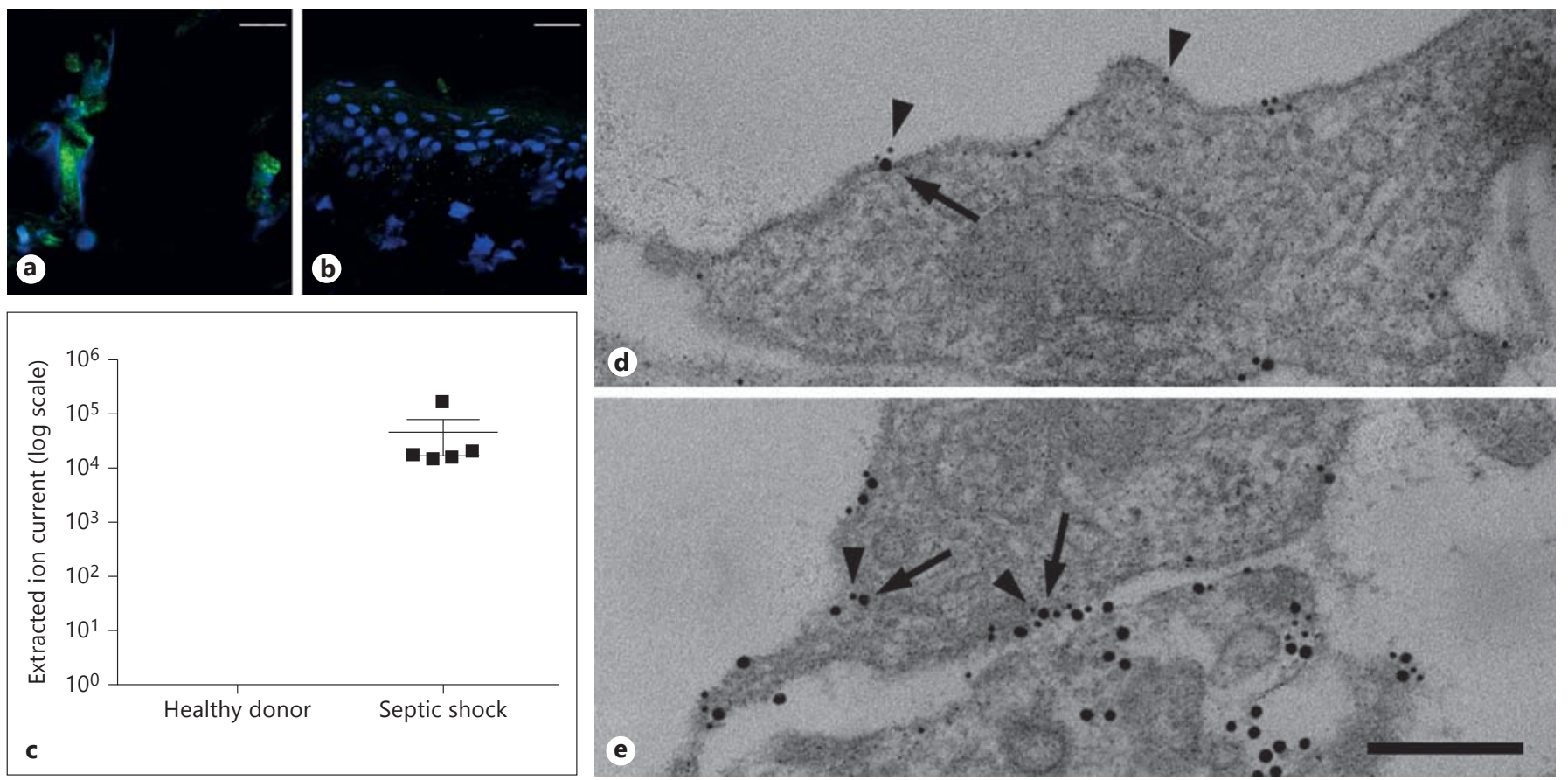

Fig. 1. Detection of extracellular histone H4. Immunostaining of tissue from a patient with cellulitis caused by an S. pyogenes infection (a) and a healthy volunteer (b) are depicted. Histones were detected with an antibody against histone $\mathrm{H} 4$. Histones are stained in green and DNA (DAPI) in blue. Scale bar: $25 \mu \mathrm{m}$. c MS data on histone $\mathrm{H} 4$ release in patients $(n=5)$ with septic shock or healthy donors $(n=5)$. Detectable amounts of histone $\mathrm{H} 4$ are presented as extracted ion current, which describes the intensity (area under curve) of a selected precursor mass from all peptides measured. d The endogenous expression of p33 (5 nm gold) on noninfected HUVEC is shown. Note, that almost no release of histone $\mathrm{H} 4$ was detected. e Treatment of HUVEC cells with S. pyogenes evokes cell necrosis and subsequent release of histone $\mathrm{H} 4(10 \mathrm{~nm}$ gold $)$ that colocalizes with endogenous p33 (5 nm gold); p33 (5 nm gold, arrowheads) and histone $\mathrm{H} 4$ (10 nm gold, arrows) were immunostained with gold-labeled antibodies. Scale bar: $100 \mathrm{~nm}$. (fig. 1e). We also noted that a significant fraction of the histones was attached to the cell membrane. Recently, we reported that endothelial cells express a negatively charged protein, also known as p33 or globular C1q receptor, which binds to antimicrobial peptides (AMPs) and thereby protects cells from a lytic attack [16]. Like AMPs, histones are positively charged, so we decided to test whether the binding of histone $\mathrm{H} 4$ to the endothelial surface is also mediated by p33. Indeed, double-immunostaining revealed that cell-bound histone $\mathrm{H} 4$ binds in close proximity to p33 (fig. 1e), supporting the notion that p33 can act as a histone-docking protein. Collectively, these data suggest that histones are released from bacteria-infected necrotic cells and can bind via p33 to the cell surface.

\section{MBP-p33 Binds to All Subclasses of Histones}

Our in vitro findings prompted us to study the interaction between histones and p33 in more detail. Microtiter plates were therefore coated with 5 histones $(\mathrm{H} 1, \mathrm{H} 2 \mathrm{~A}$,
$\mathrm{H} 2 \mathrm{~B}, \mathrm{H} 3.1$ and $\mathrm{H} 4)$ and probed with recombinantly expressed p33 fused to mannose-binding protein (MBPp33). MBP-p33 bound to all 5 subclasses, while MBP alone failed to show an interaction (fig. 2a; online suppl. fig. 1; for all online suppl. material, see www.karger.com/ doi/10.1159/363348). To study this interaction further by means of negative electron microscopy, we removed the MBP-tag by factor Xa cleavage and purified p33 by gel filtration. The micrographs depict that $\mathrm{p} 33$ (without the MBP-tag) forms a trimer that interacts with all 5 histones and that one $\mathrm{p} 33$ trimer can bind up to three ligands simultaneously (fig. 2b). Additional surface plasmon resonance experiments were performed to show that all histones bind with a high affinity (lower nanomolar range) to MBP-p33 (table 1). To map the histone-binding site in p33, we synthesized a panel of peptides spanning the entire p33 molecule. These peptides were then used in a competitive ELISA. TEA20 (net charge +2 ) was the only peptide that blocked the binding of all 5 histones to MBP-p33 (fig. 3a). These results suggest that the aminoterminal part of p33 
Fig. 2. MBP-p33 binds to all subclasses of histones. a Microtiter plates were coated with different subclasses of histones (100 $\mathrm{nM})$, probed with MBP-p33 (8 nM) and detected with a polyclonal antibody against MBP-p33. Data are mean and SE from 3 separate experiments. b Negatively stained electron micrographs of p33 in complex with gold-labeled histones are shown. The image highlights gold-labeled histones (arrows) that are in complex with p33. Scale bar: $15 \mathrm{~nm}$.



Table 1. Affinity constants for the binding of MBP-p33 to histones

\begin{tabular}{llll}
\hline Protein & $\mathrm{k}_{\mathrm{a}}\left(\mathrm{M}^{1} \mathrm{~s}^{1}\right)$ & $\mathrm{k}_{\mathrm{d}}\left(\mathrm{s}^{1}\right)$ & $\mathrm{k}_{\mathrm{D}}(\mathrm{nM})$ \\
\hline Histone H1 & $5.60 \times 10^{4}$ & $9.59 \times 10^{-4}$ & 17.1 \\
Histone H2A & $9.92 \times 10^{4}$ & $4.76 \times 10^{-3}$ & 47.9 \\
Histone H2B & $2.36 \times 10^{5}$ & $4.59 \times 10^{-3}$ & 19.4 \\
Histone H3.1 & $2.48 \times 10^{5}$ & $6.46 \times 10^{-3}$ & 26.0 \\
Histone H4 & $5.19 \times 10^{5}$ & $5.43 \times 10^{-3}$ & 10.5 \\
\hline
\end{tabular}

${ }^{1}$ Histones were injected at different concentrations over MBPp33 immobilized on a BIAcore CM3 Sensor Chip (see Materials and Methods).

(positions 115-135) is responsible for the binding to histones. In a similar approach, we dissected histone $\mathrm{H} 4$ into 6 peptides and performed an indirect ELISA to localize the p33-binding site. p33 bound exclusively to the most aminoterminal part of histone 4 (peptide MSG20; net charge +7.5 ), while no binding to the other peptides was detected (fig. 3b). To summarize, the data reveal that trimeric MBPp33 can bind up to 3 histones simultaneously with a high affinity. This interaction involves a p33-binding site, located at the amino acid positions 115-135 of p33, and a histone $\mathrm{H} 4$ binding site, positioned at the aminoterminal part (amino acid positions 1-20) of the protein.

\section{MBP-p33 Blocks the (Patho)Physiological Activities of} Histones

Having established that MBP-p33 binds with a high affinity to histones, we next wished to study whether MBP-p33 can interfere with the (patho)physiological features of histones. As histones have been described to have antimicrobial activity, we first performed viable count assays and tested the effect of histones on E. coli strain ATCC 25,922 . We found that all 5 histones displayed antimicrobial activity at concentrations of $250-500 \mathrm{nM}$, which is in the same range as that seen for many AMPs. This effect was almost completely abolished when MBPp33 was added to the reaction mixture (fig. $4 \mathrm{a}$ ). In the next series of experiments, we tested whether MBP-p33 can block histone-induced hemolysis of human erythrocytes. In the absence of MBP-p33, all 5 subclasses were very efficient in lysing erythrocytes (especially the arginine-rich histones $\mathrm{H} 3.1$ and $\mathrm{H} 4$ ); bovine $\mathrm{CTH}$, a natural mix of the 5 histones, also showed significant hemolytic activity towards erythrocytes. Preincubation of histones with equimolar concentrations of MBP-p33 completely prevented hemolysis (fig. $4 \mathrm{~b}$ ) and the same findings were noted when p33 without the MBP-tag was used (online suppl. fig. 2). Similar results were obtained in cytotoxicity assays with the endothelial cell line EA.hy926. Here, we found that MBP-p33 blocks the release of LDH from 


\begin{tabular}{|c|c|c|c|c|c|c|c|c|c|c|c|c|c|c|c|c|}
\hline \multicolumn{2}{|c|}{ p33 peptide } & LHT20 & DEI20 & LPK20 & TEA20 & TVT20 & DGE20 & QEP20 & VIK20 & CHY2O & ESD20 & TGE20 & TDS20 & FLA20 & LVE20 & LEH20 \\
\hline Protein & Charge & -4 & +3 & -1 & +2 & -4 & -7 & -4 & -1 & -7 & -4 & -4 & -3 & -4 & -4 & -1 \\
\hline Histone $\mathrm{H} 1$ & +54 & & & & * & & & & & & & & & & & \\
\hline Histone $\mathrm{H} 2 \mathrm{~A}$ & +19 & & & & * & & & & & & & & & & & \\
\hline Histone $\mathrm{H} 2 \mathrm{~B}$ & +19.5 & & & & * & & & & & & & & & & & \\
\hline Histone H3.1 & +21 & & & & * & & & & & & & & & & & \\
\hline Histone $\mathrm{H} 4$ & +19 & & & & * & & & & & & & & & & & \\
\hline
\end{tabular}

a

Fig. 3. Mapping of binding sites in MBPp33 and histone H4. a Microtiter plates were coated with histones (250 nM). Plates were then probed with MBP-p33 (33 nM) in the presence of peptides derived from p33 $(50 \mu \mathrm{M})$. Bound p33 was detected as described in Materials and Methods. The values are the mean from 3 individual experiments. Peptides that block the binding of p33 to histones are marked with an asterisk ( $<65 \%$ binding). b Microtiter plates were coated with histone $\mathrm{H} 4$-derived peptides $(1 \mu \mathrm{M})$ and probed with MBP-p33 (8 nM). Bound p33 was detected as described in Materials and Methods. Mean and SE from 4 individual experiments are shown.

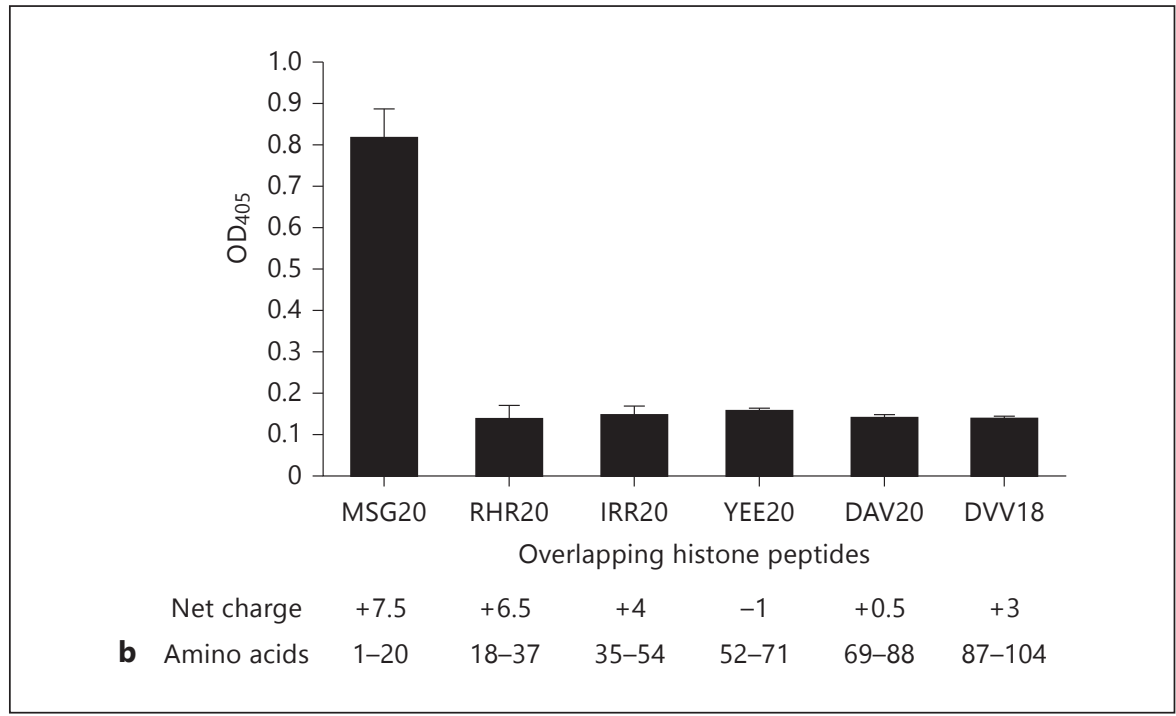

histone-treated endothelial cells (fig. 4c). It has been described that histones induce platelet aggregation by forming a complex with human fibrinogen and platelets [9]. We therefore measured histone-induced platelet aggregation over time in the absence or presence of MBP-p33. Our results showed that histone-evoked platelet aggregation is dose-dependently counteracted when MBP-p33 was added (fig. $4 \mathrm{~d}$ ). Taken together, these results show that all the physiological and pathophysiological activities of histones are blocked when they are in a complex with MBP-p33.

\section{Half-Life and Fate of MBP-p33 in vivo}

Though our in vitro data show that MBP-p33 downregulates the self-destructive features of extracellular histones, it has been described that systemic histone release contributes to life-threatening complications [25]. This finding not only suggests that extracellular histones play a crucial role in many inflammatory processes, but also indicates that the levels of endogenous p33 are not sufficient to completely neutralize their toxic activity.
We therefore decided to analyze whether the administration of exogenous MBP-p33 in mice can be used as a treatment to prevent histone-induced morbidity and mortality. To this end, we performed a couple of pilot studies and investigated whether i.v. injections of MBPp33 can evoke deleterious side effects in mice. Our results show that the application of MBP-p33 (1.5 mg/animal) was well tolerated in the animals, and no signs of toxicity or any adverse reactions could be detected. In the next series of experiments, Balb/c mice received an i.v. injection of MBP-p33 (1.5 mg/animal). Blood was collected at different time points by cardiac puncture and plasma MBP-p33 levels were determined by means of sandwich ELISA. We noted that the MBP-p33 plasma concentration was $<80 \mu \mathrm{g} / \mathrm{ml}$ already $3 \mathrm{~min}$ after injection and below the detection limit after $2 \mathrm{~h}$ (fig. 5a). Considering the molecular weight of trimeric MBP-p33 (226 kDa), the rapid clearance from the plasma was unexpected and we therefore decided to further follow the fate of injected MBP-p33. MBP-p33 was labeled with a fluorescent dye and the i.v.-injected protein was detected over time by 


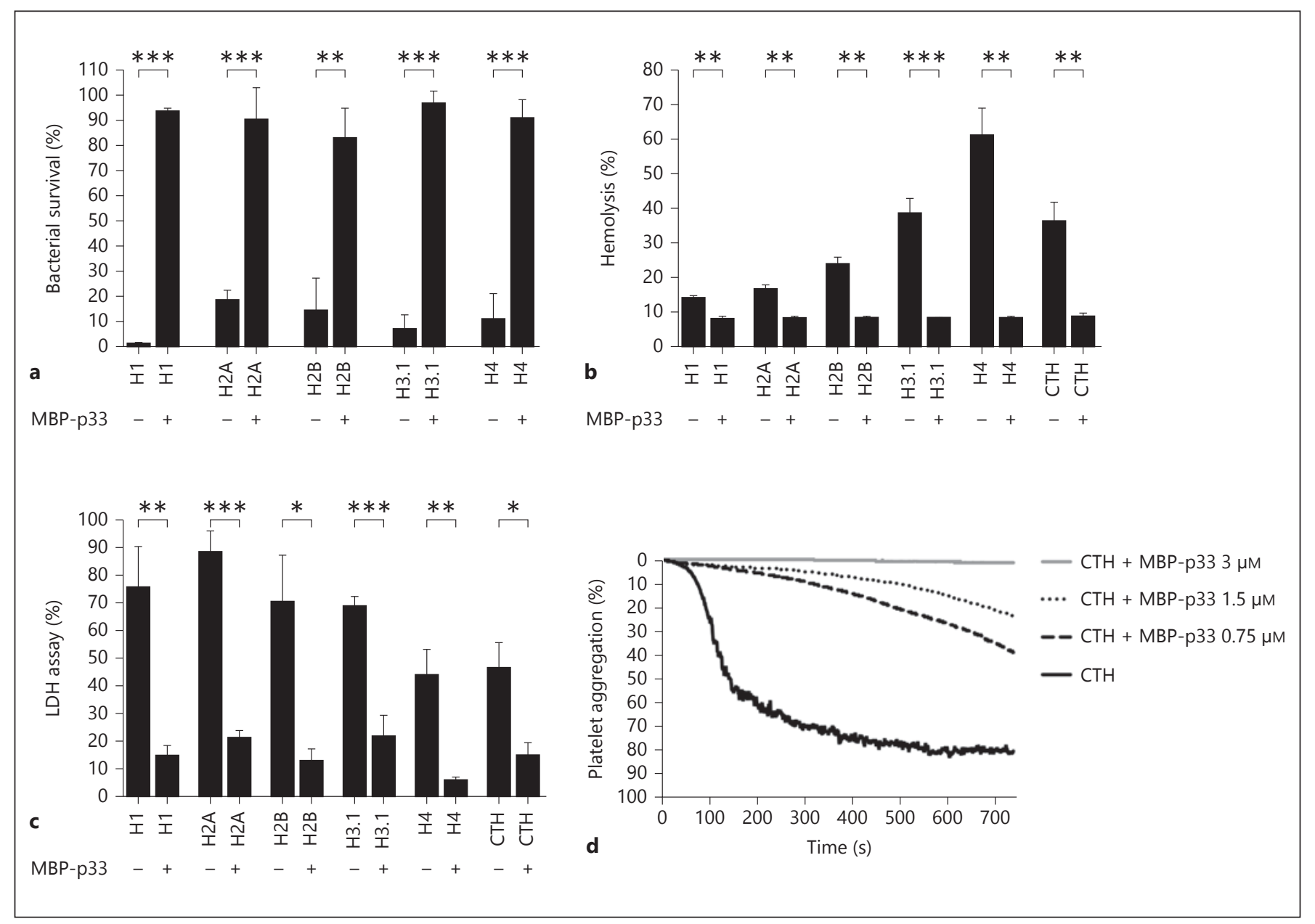

Fig. 4. Functional inhibition of histones by MBP-p33. a The bactericidal activity of histones is neutralized by $\mathrm{p} 33$. Histone $\mathrm{H} 1$ (500 $\mathrm{nM})$, histone $\mathrm{H} 2 \mathrm{~A}(500 \mathrm{nM})$, histone $\mathrm{H} 2 \mathrm{~B}$ (500 nM), histone H3.1 $(500 \mathrm{nM})$ and histone $\mathrm{H} 4(250 \mathrm{nM})$ were incubated with $2 \times 10^{6}$ $\mathrm{CFU} / \mathrm{ml}$ bacteria (E. coli strain ATCC 25922) in the presence or absence of $2.5 \mu \mathrm{M}$ MBP-p33. Samples were plated on Todd-Hewitt agar plates and colonies were counted the following day. Data are mean and SE from 3 separate experiments. ${ }^{* * *} \mathrm{p}<0.001,{ }^{* *} \mathrm{p}<$ $0.01,{ }^{*} \mathrm{p}<0.05$. b MBP-p33 blocks the cytolytic effect of histones. Histones $(10 \mu \mathrm{M})$ were incubated with washed human erythrocytes in the presence or absence of $10 \mu \mathrm{M}$ MBP-p33. Samples were centrifuged and hemolysis was measured at $540 \mathrm{~nm}$ in the supernatant. Hemolysis was calculated as percentage of cells treated with Tox-7 lysis buffer. Data are mean and SE from 3 separate experiments. ${ }^{* * *} \mathrm{p}<0.001,{ }^{* *} \mathrm{p}<0.01,{ }^{*} \mathrm{p}<0.05$. c MBP-p33 inhibits

fluorescence imaging in an IVIS Spectrum station. Three minutes after injection, strong fluorescence signals were detected, especially on body parts with less fur (the tail, hindlimbs and nose); staining was also detected on the torso (fig. 5b). In contrast to the ELISA data, the intensity of the signals declined only slowly over time and $24 \mathrm{~h}$ histone-induced LDH release from endothelial cells. Confluent EA.hy926 cells were treated overnight with histone $\mathrm{H} 1(4 \mu \mathrm{M})$, histone $\mathrm{H} 2 \mathrm{~A}(4 \mu \mathrm{M})$, histone $\mathrm{H} 2 \mathrm{~B}(4 \mu \mathrm{M})$, histone $\mathrm{H} 3.1(4 \mu \mathrm{M})$, histone $\mathrm{H} 4(2 \mu \mathrm{M})$ or CTH $(50 \mu \mathrm{g} / \mathrm{ml})$ in the presence or absence of $10 \mu \mathrm{M}$ MBP-p33. LDH release was measured in the supernatant. Cell lysis was calculated as the percentage of cells treated with Tox-7 lysis buffer. Data are mean and SE from 3 separate experiments. ${ }^{* * *} \mathrm{p}<$ $0.001,{ }^{* *} \mathrm{p}<0.01,{ }^{*} \mathrm{p}<0.05$. d MBP-p33 prevents histone-triggered platelet aggregation. CTH $(300 \mu \mathrm{g} / \mathrm{ml})$ were added to platelet-rich plasma in the presence or absence of increasing concentrations of MBP-p33 (0.65-6.2 $\mu \mathrm{M})$. Platelet aggregation was monitored for $12 \mathrm{~min}$ and was calculated as the percentage of light transmission through each sample with platelet-poor plasma in a reference channel. One representative experiment out of 3 is shown. 
Fig. 5. Half-life time of MBP-p33 in murine blood samples and its deposition in the tissue. a MBP-p33 was i.v. injected into Balb/c mice and the disappearance of MBP-p33 was measured in the mouse plasma at different time points with a sandwich ELISA. b Fluorescently labeled MBP-p33 was i.v. injected into a Balb/c mouse and its distribution in the animal was followed for $24 \mathrm{~h}$ by an IVIS Spectrum station.



that MBP-p33 was not cleared from the body and was probably attached to the blood vessels and the perfused organs.

\section{p33 Prevents Histone-Induced Hemolysis,}

\section{Thrombocytopenia and Lung Damage in vivo}

High concentrations of histones injected i.v. into mice can cause $100 \%$ mortality within minutes. However, at lower concentrations, histones may disrupt the hemostatic equilibrium and eventually trigger pathological symptoms that resemble many complications that are seen under the conditions of septic shock $[8,9,11,26]$. To test whether MBP-p33 counteracts these host responses, we injected nonlethal doses of CTH $(0.75 \mathrm{mg} / \mathrm{animal})$ i.v. into mice in the absence or presence of MBP-p33. Animals receiving an injection with $\mathrm{PBS}$ only were used as a control. Ten minutes after the injection, mice were eu- thanized and blood was collected to prepare plasma samples. We found that plasma from $\mathrm{CTH}$-treated animals was hemolytic, but no hemolysis was detected in the plasma of the mice treated with CTH and MBP-p33 or in the controls (fig. 6a). Thrombocytopenia resulting from platelet depletion can constitute a severe complication in patients with severe infectious diseases. In 2011, Fuchs et al. [9] reported that injection of nonlethal doses of histones triggers thrombocytopenia in mice. In our experiments, we also measured significant platelet depletion in the blood from $\mathrm{CTH}$-challenged mice. However, when MBP-p33 was coadministered with CTH, platelet counts were in a range similar to that seen in the control samples (fig. 6b). Hemolytic disorders often lead to pulmonary damage, so we analyzed the lungs of the animals. Scanning electron microscopy revealed that the mice injected with CTH suffered from severe pulmonary lesions caused 

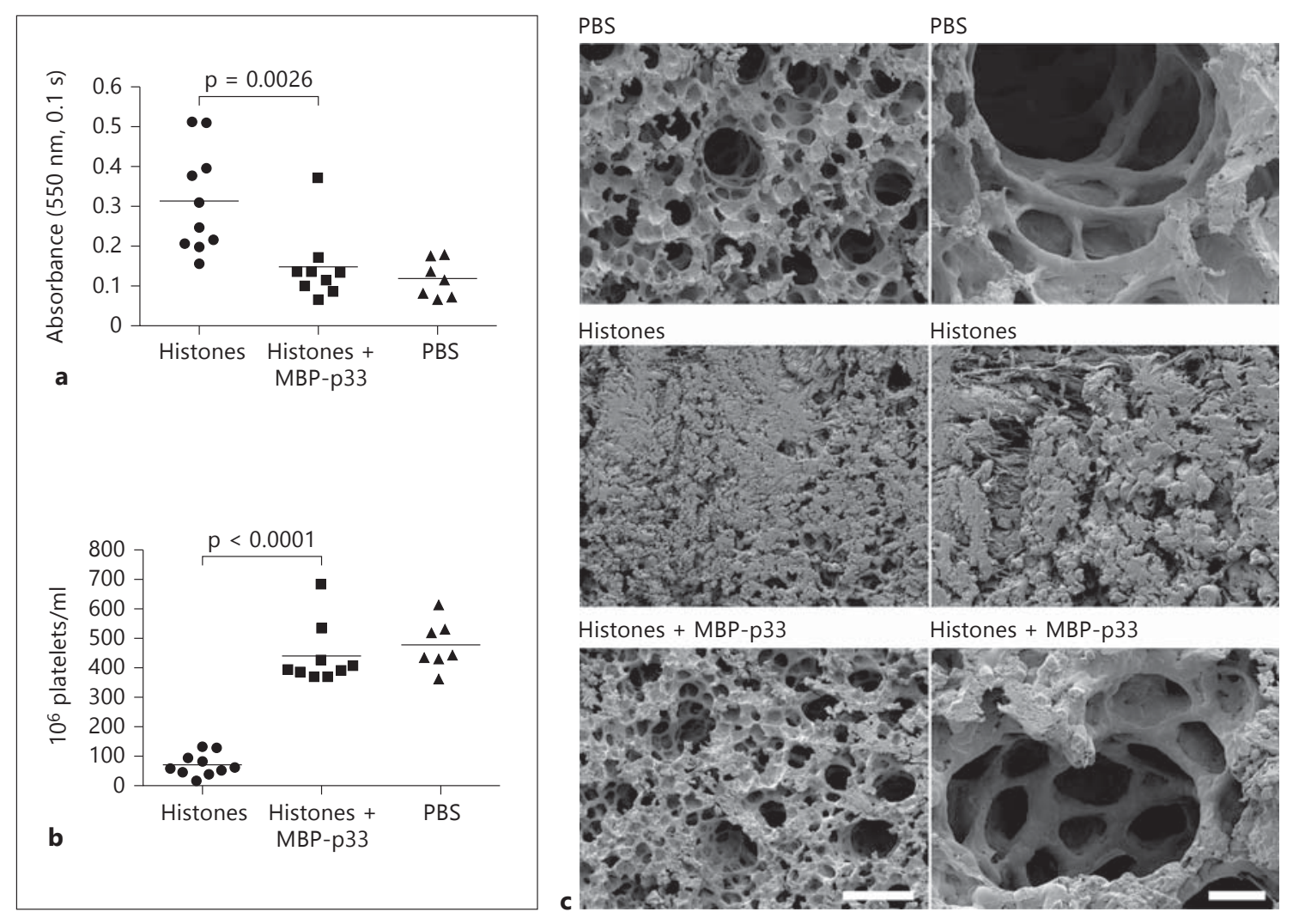

Fig. 6. In vivo effects of MBP-p33 in mice challenged with CTH. a MBP-p33 prevents histone-induced hemolysis. Mice were i.v. injected with a nonlethal dose of CTH $(0.75 \mathrm{mg} / \mathrm{animal})$ in the presence $(n=9)$ or absence $(n=10)$ of MBP-p33 $(1.5 \mathrm{mg} /$ animal $)$ for $2 \mathrm{~h}$. PBS-treated animals $(10 \mathrm{~min})$ served as controls $(\mathrm{n}=7)$. Blood was drawn by cardiac puncture and then centrifuged at 2,000 $\mathrm{g}$. Hemolysis was determined by measuring the absorbance

at $540 \mathrm{~nm}$ in the supernatants. b MBP-p33 blocks histone-induced thrombocytopenia. The platelet count was measured in the blood samples from animals treated with CTH, CTH/MBP-p33 or PBS for $2 \mathrm{~h}$. All platelet counts were determined by a Vetscan HM5. c MBP-p33 prevents histone-induced tissue damage in the lungs. The panel shows representative micrographs of lung sections from mice treated with PBS, CTH or CTH/MBP-p33 for $2 \mathrm{~h}$.

by deposited fibrin fibers and aggregated erythrocytes (fig. 6c, middle panel). The presence of MBP-p33 clearly decreased these histone-induced effects, though the alveoli still appeared to be slightly swollen and some small traces of fibrin and erythrocytes were detected (fig. 6c, bottom panel). The lungs from the PBS-injected mice served as controls (fig. 6c, top panel). All together, the in vivo data show that coapplication of MBP-p33 dramatically diminished morbidity in the mice challenged with a toxic dose of histones.

MBP-p33 Rescues Mice from a Lethal Dose of Histones In the last set of experiments, we wished to test whether MBP-p33 has protective effects against lethal doses of histones. To this end, we performed a survival study with $\mathrm{Balb} / \mathrm{c}$ mice receiving an i.v. injection of CTH $(1.5 \mathrm{mg} /$ animal) in the absence or presence of MBP-p33. They

were monitored for 7 days by measuring body weight and temperature on a daily basis. As reported in other studies $[8,9]$, we observed that all mice receiving only CTH died within $15 \mathrm{~min}$. However, when $\mathrm{CTH}$-challenged mice were treated with MBP-p33, the mortality rate was as low as $50 \%$, and the first lethal case was recorded $2 \mathrm{~h}$ after the injection (fig. 7). Note that the surviving mice maintained a stable weight and body temperature and were fully recovered after a couple of days. When MBP-p33 was injected in the absence of CTH as a control, it was found that this treatment did not influence health status, body weight or temperature. To summarize, we found that MBP-p33 is a potent inhibitor of histones. Our data also suggest that MBP-p33 is a promising drug candidate for treatment of the histone-mediated complications seen in many pathological conditions including severe infectious diseases. 


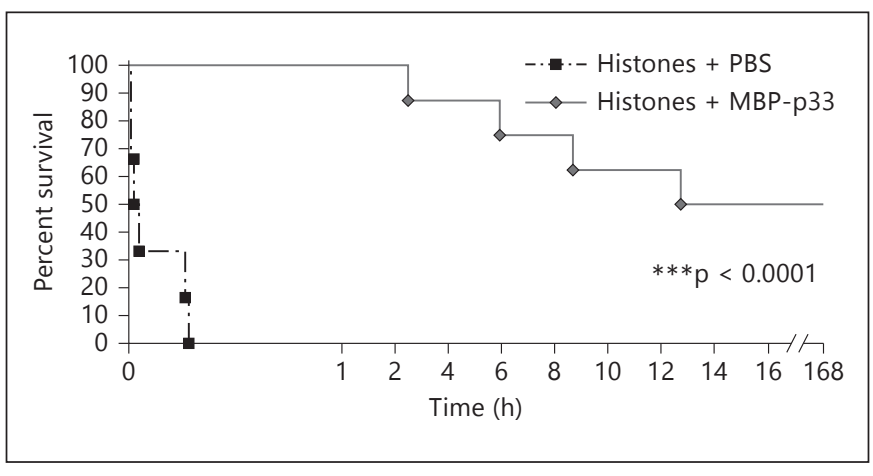

Fig. 7. MBP-p33 rescues mice from a lethal injection of histones. Mice were subjected to an i.v. injection of a lethal dose of CTH (1.5 $\mathrm{mg}$ /animal) in the presence $(\mathrm{n}=8)$ or absence $(\mathrm{n}=6)$ of MBP-p33 (1.5 mg/animal). Survival was monitored for 7 days.

\section{Discussion}

Initially, p33 (also known as globular C1q receptor) was described as a receptor for the globular heads of $\mathrm{Clq}$ [27]. Later, it was found that the protein also interacts with other plasma proteins including vitronectin, highmolecular-weight kininogen and the coagulation factors XII and thrombin [28]. In addition to these ligands, a number of bacterial and viral proteins have been identified that can bind either to surface-bound or intracellular p33 [28]. While the interactions of bacterial proteins with membrane-attached p33 is thought to promote cell adhesion and internalization of the pathogen [29-31], the interaction with viral proteins mainly takes place intracellularly and, in some cases, this has been shown to suppress virus replication [28]. Recently, we reported that p33 exhibits a high affinity for another group of proteins/peptides, namely AMPs. Our data show that this interaction impairs the bactericidal and cytotoxic features of AMPs and prevents AMP-evoked cell necrosis [16]. It is noteworthy that extracellular histones and AMPs have features in common [32]. For instance, histones are like AMPs, highly cationic, rich either in lysine (H1, H2A and $\mathrm{H} 2 \mathrm{~B})$ or arginine (H3.1 and H4) [33]. Moreover, they exert antimicrobial activity against several Gram-positive and Gram-negative pathogens and are cytotoxic towards many cell types $[8$, $10,26,33]$. These similarities prompted us to study the interaction between p 33 and histones in more detail and to test whether p33 could be used in therapeutic settings.

Our results show that histones are released from necrotic tissue at the site of infection in patients with strep-

p33 Neutralizes the Toxicity of

Extracellular Histones tococcal skin infections. We also recorded elevated histone levels in the plasma samples of patients suffering from septic shock. These findings suggested a chain of events that could provide an explanation for the rise of histones in the circulation of these patients, and this was the starting point for us to study the interaction between p33 and histones in more detail. To this end, we investigated the histone-p33 interaction with several biochemical approaches, i.e. ELISA, surface plasmon resonance and electron microscopy. We found that p33 bound all subclasses of histones with a high affinity (a lower nanomolar range). Further analysis revealed that p33 is able to block all tested functional features of histones, i.e. their antimicrobial activity, cytotoxic properties and ability to evoke platelet aggregation. Our in vitro results suggest that cell necrosis and platelet aggregation caused by extracellular histones cannot be completely compensated by endogenous membrane-bound $\mathrm{p} 33$. We therefore wished to test whether the administration of $\mathrm{p} 33$ can be used for therapeutic purposes. For this reason, we injected pathological doses of histones i.v. into mice and recorded increased hemolysis, platelet depletion and lung injury. These complications were efficiently prevented when p33 was coadministered in these experiments. At higher concentrations, histones have been shown to evoke death within minutes, as reported by Fuchs et al. [9], who demonstrated that this was triggered by profound thrombocytopenia caused by histone-fibrinogen-platelet complexes. In our experiments, we also noted that the injection of lethal histone doses caused $100 \%$ mortality in mice (in $<15 \mathrm{~min}$ ). However, when the mice were treated with p33, we found that all the animals survived the first $2.5 \mathrm{~h}$ and that after 7 days, $50 \%$ of the mice had not only survived, but were fully recovered.

These findings may have important therapeutic applications in severe infectious diseases, as the early administration of a proper treatment can have a significant impact on disease outcome. For instance in 2006, Kumar et al. [34] reported that for each hour that an antimicrobial therapy is delayed in patients with septic shock, mortality could increase by $7.6 \%$. Many complications seen in these patients are caused by a pathological overreaction of hostdefense responses and, thus, it is obvious that targeting the pathogen only cannot dampen these self-destructive reactions, because they have already been initiated. A massive release of histones has an immediate deleterious effect, so their inhibition in combination with a conventional antimicrobial treatment is a promising therapeutic approach for overcoming this early critical phase. This, in 
turn, can have life-prolonging effects and facilitate subsequent treatments. Our data show that $\mathrm{p} 33$ is a potential drug candidate for use in sepsis studies. Taken together, the results we have presented show that the interaction of p33 with extracellular histones blocks pathological host responses and that administration of p33 curtails both morbidity and mortality in a murine model for histoneinduced shock.

\section{Acknowledgements}

We wish to thank Pia Andersson and Maria Baumgarten for excellent technical assistance. This work was supported in part by the foundations of Alfred Österlund, Crafoord, Greta and Johan Kock, the Knut and Alice Wallenberg Foundation, the Ragnar Söderberg Foundation, Sten K Johnson, Sven-Olof Janson Lifework, the Medical Faculty at Lund University, the Swedish Foundation for Strategic Research and the Swedish Research Council.

\section{References}

-1 Holdenrieder S, Stieber P, Bodenmuller H, Fertig G, Furst $\mathrm{H}$, et al: Nucleosomes in serum as a marker for cell death. Clin Chem Labor Med 2001;39:596-605.

-2 Saffarzadeh M, Juenemann C, Queisser MA, Lochnit G, Barreto G, et al: Neutrophil extracellular traps directly induce epithelial and endothelial cell death: a predominant role of histones. PLoS One 2012;7:e32366.

-3 Abrams ST, Zhang N, Manson J, Liu TT, Dart $\mathrm{C}$, et al: Circulating histones are mediators of trauma-associated lung injury. Am J Respir Crit Care Med 2013;187:160-169.

-4 Amoura Z, Piette JC, Chabre H, Cacoub P, Papo T, et al: Circulating plasma levels of nucleosomes in patients with systemic lupus erythematosus - correlation with serum antinucleosome antibody titers and absence of clear association with disease activity. Arthritis Rheum 1997;40:2217-2225.

$\checkmark 5$ Gillrie MR, Lee K, Gowda DC, Davis SP, Monestier M, et al: Plasmodium falciparum histones induce endothelial proinflammatory response and barrier dysfunction. Am J Pathol 2012;180:1028-1039.

-6 Holdenrieder S, Stieber P, Bodenmuller H, Busch M, Fertig G, et al: Nucleosomes in serum of patients with benign and malignant diseases. Int J Cancer 2001;95:114-120.

-7 Kutcher ME, Xu J, Vilardi RF, Ho C, Esmon $\mathrm{CT}$, et al: Extracellular histone release in response to traumatic injury: implications for a compensatory role of activated protein C. J Trauma Acute Care Surg 2012;73:1389-1394

-8 Xu J, Zhang XM, Pelayo R, Monestier M, Ammollo CT, et al: Extracellular histones are major mediators of death in sepsis. Nat Med 2009;15:1318-1321.

$\checkmark 9$ Fuchs TA, Bhandari AA, Wagner DD: Histones induce rapid and profound thrombocytopenia in mice. Blood 2011;118:3708-3714.

10 Kleine TJ, Lewis PN, Lewis SA: Histone-induced damage of a mammalian epithelium: the role of protein and membrane structure. Am J Physiol Cell Physiol 1997;273:C1925-C1936.

11 Xu J, Zhang XM, Monestier M, Esmon NL, Esmon CT: Extracellular histones are mediators of death through TLR2 and TLR4 in mouse fatal liver injury. J Immunol 2011;187:2626-2631.

-12 Semeraro F, Ammollo CT, Morrissey JH, Dale GL, Friese P, et al: Extracellular histones promote thrombin generation through plate- 23 Green RJ, Dafoe DC, Raffin TA: Necrotizing let-dependent mechanisms: involvement of platelet TLR2 and TLR4. Blood 2011;118: 1952-1961.

13 Zeerleder S, Zwart B, Wuillemin WA, Aarden LA, Groeneveld ABJ, et al: Elevated nucleosome levels in systemic inflammation and sepsis. Crit Care Med 2003;31:1947-1951.

14 Abrams ST, Zhang N, Dart C, Wang SS, Thachil J, et al: Human CRP defends against the toxicity of circulating histones. J Immuno 2013;191:2495-2502.

15 Nakahara M, Ito T, Kawahara K, Yamamoto M, Nagasato T, et al: Recombinant thrombomodulin protects mice against histone-in duced lethal thromboembolism. PLoS One 2013;8:e75961.

16 Westman J, Hansen FC, Olin AI, Mörgelin M, Schmidtchen A, et al: p33 ( $\mathrm{gClq}$ receptor) prevents cell damage by blocking the cytolytic activity of antimicrobial peptides. J Immunol 2013;191:5714-5721.

17 Thulin P, Johansson L, Low DE, Gan BS, Kotb $M$, et al: Viable group A streptococci in macrophages during acute soft tissue infection. PLoS Med 2006;3:371-379.

18 Karlsson C, Malmstrom L, Aebersold R, Malmstrom J: Proteome-wide selected reaction monitoring assays for the human pathogen Streptococcus pyogenes. Nat Commun 2012;3:1301.

19 Bernhardt OM, Selevsek N, Gillet L, Rinner $\mathrm{O}$, Picotti P, et al: Spectronaut: a fast and efficient algorithm for MRM-like processing of data independent acquisition (SWATH-MS) data. Proceedings of the 60th ASMS Conference on Mass Spectrometry, 2012.

20 Reiter L, Rinner O, Picotti P, Huttenhain R, Beck M, et al: mProphet: automated data processing and statistical validation for largescale SRM experiments. Nat Methods 2011;8: U430-U485.

21 Abdillahi SM, Balvanovic S, Baumgarten M, Mörgelin M: Collagen VI encodes antimicrobial activity: novel innate host defense properties of the extracellular matrix. J Innate Immun 2012;4:371-376.

22 Edgell CJ, Mcdonald CC, Graham JB: Permanent cell-line expressing human factor-VIIIrelated antigen established by hybridization. Proc Natl Acad Sci USA Biol Sci 1983;80: 3734-3737. fasciitis. Chest 1996;110:219-229.

-24 Gonzalez BE, Martinez-Aguilar G, Hulten KG, Hammerman WA, Coss-Bu J, et al: Severe staphylococcal sepsis in adolescents in the era of community-acquired methicillinresistant Staphylococcus aureus. Pediatrics 2005; 115:642-648.

25 Chaput C, Zychlinsky A: Sepsis: the dark side of histones. Nat Med 2009; 15:1245-1246.

26 Kleine TJ, Gladfelter A, Lewis PN, Lewis SA: Histone-induced damage of a mammalian epithelium - the conductive effect. Am J Physiol Cell Physiol 1995;268:C1114-C1125.

27 Ghebrehiwet B, Lim BL, Peerschke EIB, Willis $A C$, Reid KBM: Isolation, cDNA cloning, and overexpression of a 33-kD cell-surface glycoprotein that binds to the globular heads of C1q. J Exp Med 1994;179:1809-1821.

28 Ghebrehiwet B, Jesty J, Vinayagasundaram R, Vinayagasundaram U, Ji Y, et al: Targeting $\mathrm{gClqR}$ domains for therapy against infection and inflammation. Adv Exp Med Biol 2013; 734:97-110.

29 Braun L, Ghebrehiwet B, Cossart P: gClq-R/ $\mathrm{p} 32$, a C1q-binding protein, is a receptor for the InlB invasion protein of Listeria monocytogenes. ЕMBO J 2000;19:1458-1466.

30 Ghebrehiwet B, Tantral L, Titmus MA, Panessa-Warren BJ, Tortora GT, et al: The exosporium of $B$. cereus contains a binding site for $\mathrm{gClqR} / \mathrm{p} 33$ : implication in spore attachment and/or entry. Curr Topics Innate Immun 2007;598:181-197.

-31 Nguyen T, Ghebrehiwet B, Peerschke EIB: Staphylococcus aureus protein A recognizes platelet $\mathrm{gC} 1 \mathrm{qR} / \mathrm{p} 33$ : a novel mechanism for staphylococcal interactions with platelets. Infect Immun 2000;68:2061-2068.

32 Choi KY, Chow LNY, Mookherjee N: Cationic host defence peptides: multifaceted role in immune modulation and inflammation. J Innate Immun 2012;4:361-370.

33 Hirsch JG: Bactericidal action of histone. J Exp Med 1958;108:925-944.

34 Kumar A, Roberts D, Wood KE, Light B, Parrillo JE, et al: Duration of hypotension before initiation of effective antimicrobial therapy is the critical determinant of survival in human septic shock. Crit Care Med 2006;34:15891596. 